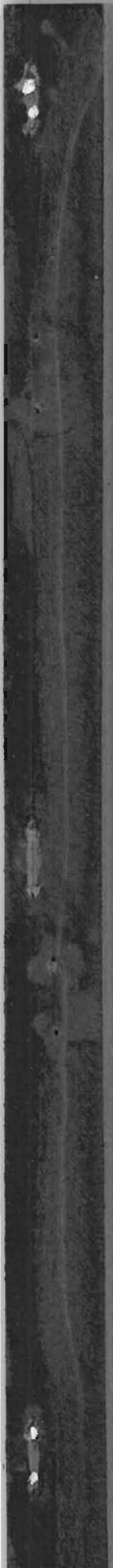

BNWL-203

$25-$

\title{
TRANSFORMATION RATES OF
}

\section{PLASTICALLY DEFORMED PLUTONIUM}

\section{DEVELOPMENT}

\section{REPORT}

\author{
R. D. NELSON
}

MARCH， 1966

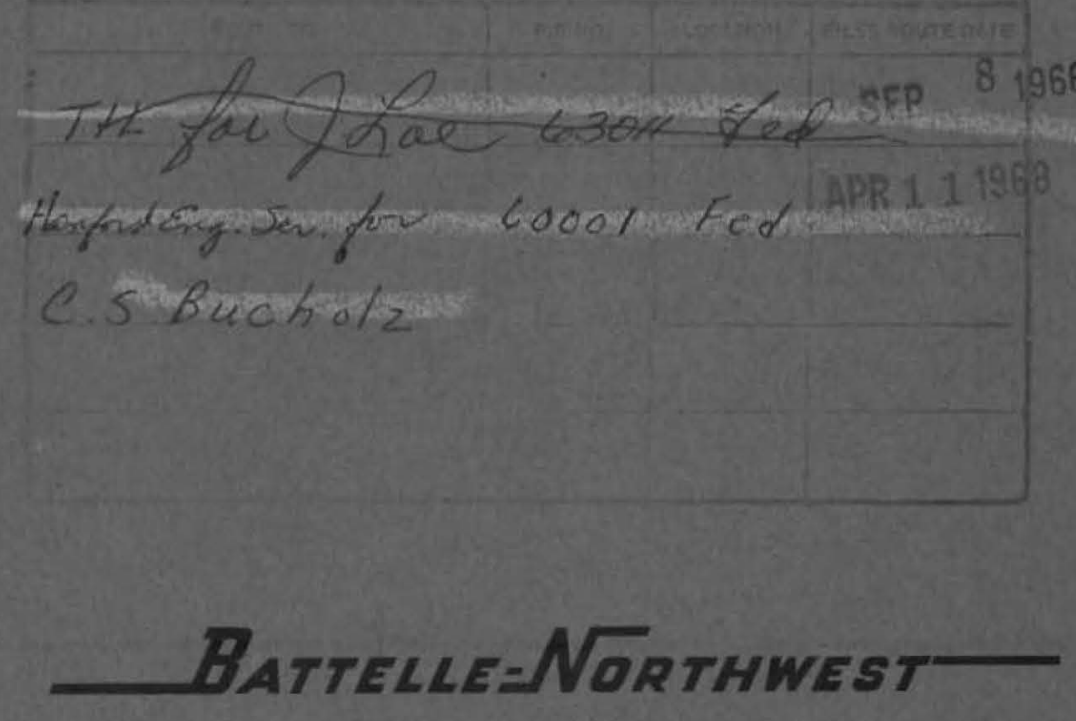

BATTELLE MEMORIAL INSTITUTE / PACIFIC NORTHWEST LABORATORY 


\section{LEGAL NOTICE}

This report was prepared as an account of Government sponsored work. Neither the United States, nor the Commission, nor any person acting on behalf of the Commission:

A. Makes any warronfy or representation, expressed or implied, with respect to the occuracy, com: pleteness, or usefulness of the informetion contained in this report, or that the use of ony information apparafus, method, or process disclosed in this report moy not infringe privately owned rights or

B. Assumes any liabilities with respect to the use of, or for damages resulting from the use of any information, apparatus, method, or process disclosed in this report.

As used in the above, "person acting on behaif of the Commission" includes any employee or controctor of the Commission, or employes of such contractor, to the extent that suctr employee of contractar of the Cammission, or employee of such contractor prepares, disseminates, or provides access to. any information pursuant to his employment or contract with the Commission, of his employment with such controctor

PACIFIC NORTHWEST LABORATORY

RICHLAND, WASHINGTON:

operated by

BATTELLE MEMORIAL INSTITUTE

for the

UNIYED STATES ATOMIC ENERGY COMMISSION UNDER CONTRACT AT(45-1)-1830 


\section{ABSTRACT}

Plastic deformation of the stable beta phase in plutonium retards the $\beta \rightarrow \alpha$ transformation. This is consistent with known martensitic transformations. There are insufficient dislocations in plastically deformed alpha to retard $\alpha \rightarrow \beta$ transformation, but sufficient dislocations are present to accelerate it. Deformed alpha plutonium can be annealed at $105^{\circ} \mathrm{C}$. 


\section{2}

BNWL - 203

$$
\text { UC-25, Metals, }
$$

Ceramics, and Materials

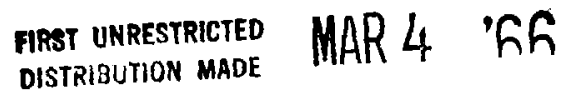

TRANSFORMATION RATES OF PLASTICALLY DEFORMED PLUTONIUM

By

R. D. Nelson

February, 1966

PACIFIC NORTHWEST LABORATORY

RICHLAND, WASHINGTON 


\section{TRANSFORMATION RATES OF PLASTICALLY DEFORMED PLUTONIUM}

\section{INTRODUCTION}

The effect of plastic deformation of the stable parent phase on the kinetics of the subsequent $\beta \rightarrow \alpha$ and $\alpha \rightarrow \beta$ transformations in plutonium was studied to provide information on the mechanics of these transformations. The results are discussed, and they are compared to results from similar experiments on other metals and alloys.

The parent phase of a martensitic transformation will be stabilized by significant amounts of plastic deformation. Plastic deformation of the stable parent phase may either depress the $M_{S}$ temperature or slow the isothermal transformation rate, whichever is applicable. This inhibiting effect of plastic deformation, the lowering of transformation rates, is referred to as mechanical stabilization, and has been observed in iron alloys $(1-7)$. Plastic deformation of the parent phase is known to decrease the rates of martensitic transformations in the systems, cerium ${ }^{(7)}$ and cobalt ${ }^{(8)}$, as wel1 as the iron alloys. The reduction of transformation rates of the stable parent phase has not been observed in diffusional transformations. On the contrary, plastic deformation always accelerates diffusional transformations because it promotes nucleation and growth(9).

The effect of plastic deformation of a stable parent phase on transformation rates is to be differentiated from the effect of plastic deformation of an unstable parent phase. The transformation rate is accelerated by plastic deformation of the unstable parent phase for both martensitic and diffusion controlled transformations $(10-12)$; the extent of the effect depends upon the sluggishness of the transformation.

Fiedler, Averbach, and Cohen (1) found that plastic strains up to $2 \%$ elongation in the stable parent phase favored the 
austenite $\rightarrow$ martensite transformation, but plastic strains above $2 \%$ elongation hindered the subsequent transformation. They suggested that mechanical stabilization of this alloy was due to the distorted structure of the deformed austenite; the high dislocation density and deformed lattice of the cold-worked austenite interferes with the propagation of martensite, but residual stresses may assist nucleation. Kurdjumov $(13,14)$ observed similar mechanical stabilization in a steel containing $0.954 \% \mathrm{C}$ and $3.5 \% \mathrm{Mn}$.

Thus, the effects of plastic deformation of the parent beta and alpha phases on the $\beta \rightarrow \alpha$ and $\alpha \rightarrow \beta$ transformations were determined to see whether the results are consistent with known martensitic transformations.

INFLUENCE OF BETA PLASTIC DEFORMATION ON THE $\beta \rightarrow \alpha$ TRANSFORMATION KINETICS

The influence of the plastic deformation of beta plutonium on a subsequent transformation to the alpha phase was investigated. A series of specimens from the same melt were transformed from alpha to beta at $160{ }^{\circ} \mathrm{C}$ and then compressed in the range 0 to $95 \%$ reduction in thickness at $140^{\circ} \mathrm{C}$ and $150^{\circ} \mathrm{C}$. The beta phase formed from alpha is hereafter designated $\beta_{\alpha}$. The specimens were allowed to transform to the alpha phase at $80^{\circ} \mathrm{C}$. This transformation temperature yielded reasonable times for the start of the $\beta_{\alpha} \rightarrow$ a transformation in specimens that were or were not plastically deformed.

Typical $\beta_{\alpha} \rightarrow \alpha$ isothermal reaction curves of undeformed and deformed metal are given in Figure 1 . Density measurements at $80^{\circ} \mathrm{C}$ permitted the isothermal reaction process to be followed. The data shows that beta plastic deformation increases the $\beta_{\alpha} \rightarrow \alpha$ incubation time and decreases the $\beta_{\alpha} \rightarrow$ a transformation rate. Plastic deformation of $\beta_{\alpha}$ at $140^{\circ} \mathrm{C}$ followed by transformation to alpha at $80^{\circ} \mathrm{C}$ produced alpha metal having a very nonrandom 


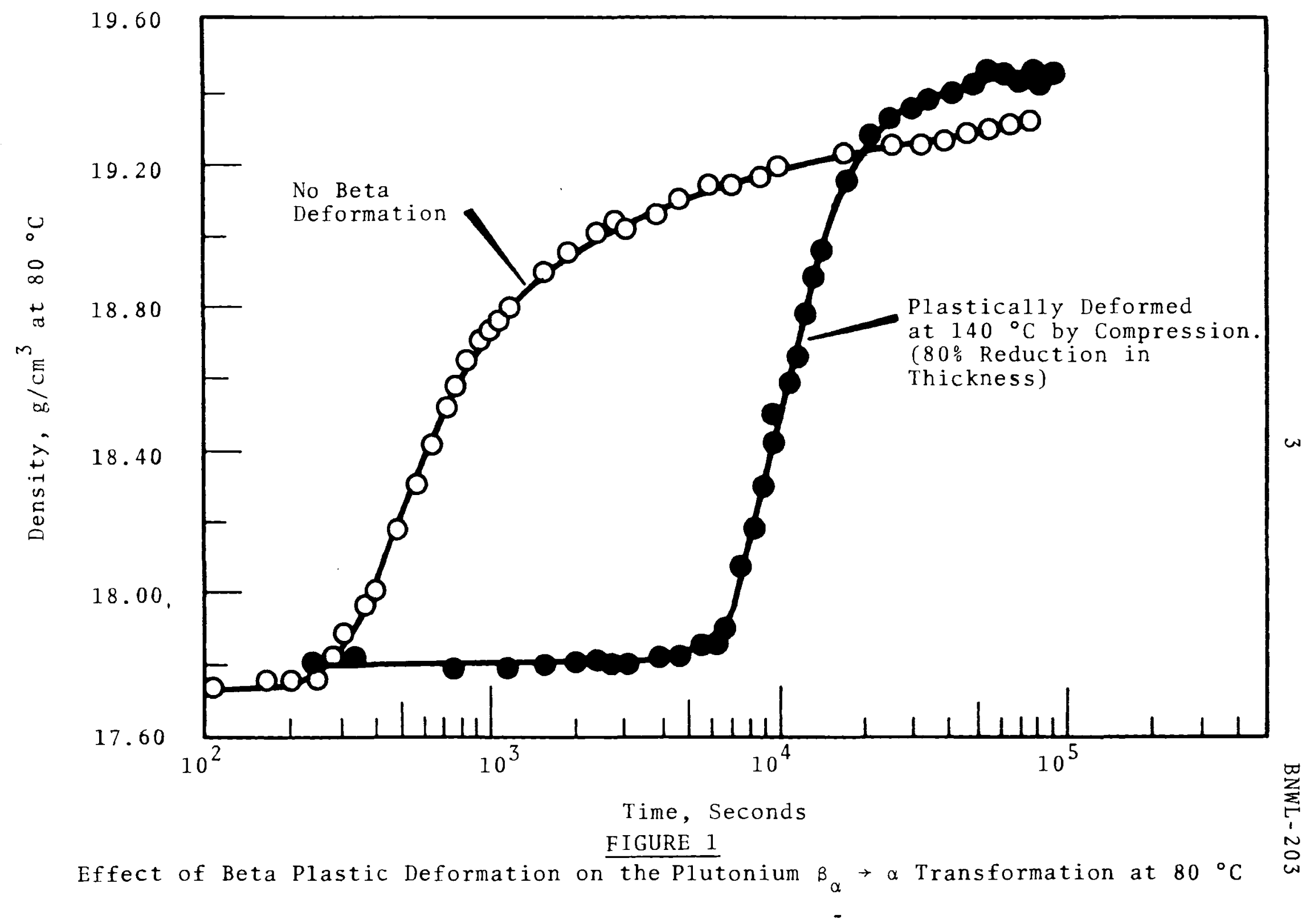


grain structure. The metal consists of bands of columnar grains as shown in Figure 2 (Note extensive banding caused by the plastic formation polarized light). Banding in deformed specimens is much greater than in undeformed specimens with similar thermal treatments.

Similar experiments were performed on beta phase plutonium that had been formed from gamma, hereafter designated $\beta_{\gamma}$. Plastic deformation of $\beta_{\gamma}$ increased the time for start of the $\beta_{\gamma} \rightarrow \alpha$ transformation. Plastic deformation of $\beta_{\gamma}$ also markedly decreased the $\beta_{\gamma} \rightarrow \alpha$ transformation rate. Because the $\beta_{\gamma} \rightarrow \alpha$ transformation rate is greater than the $\beta_{\alpha} \rightarrow \alpha$ transformation rate, ${ }_{\gamma}$ specimens were transformed to alpha at temperatures higher than $80^{\circ} \mathrm{C}$ to yield approximately equal transformation rates for the undeformed beta phase. The maximum $\beta_{\gamma} \rightarrow \alpha$ transformation rate and incubation time at $90^{\circ} \mathrm{C}$ equalled the maximum $\beta_{\alpha} \rightarrow \alpha$ transformation rate and incubation time.

The study of the effect of deformation temperature on the $B_{\gamma} \rightarrow \alpha$ and $B_{\alpha} \rightarrow \alpha$ transformations in specimens reduced 75 to $85 \%$ in thickness by compression showed that increased deformation temperatures resulted in slower transformation rates for both the $\beta_{\alpha} \rightarrow \alpha$ and $\beta_{\gamma} \rightarrow \alpha$ (Figure 3 ). Apparent1y, a critical amount of beta deformation is needed to decrease the $\beta \rightarrow \alpha$ transformation rate. As shown in Figure 4, this critical amount is about $10 \%$ for deformation by compression at $150{ }^{\circ} \mathrm{C}$. For deformation be yond this amount, the transformation rate decreases with increasing prior deformation.

Because the rates of diffusion controlled transformations are normally increased, rather than decreased, by plastic deformation, it is inferred that diffusion of individual atoms is not a major part of the $\beta \rightarrow \alpha$ transformation because plastic deformation retards the $\beta \rightarrow \alpha$ transformation. The observed effects of plastic deformation appear to parallel those for which the concept 
BNWL- 203

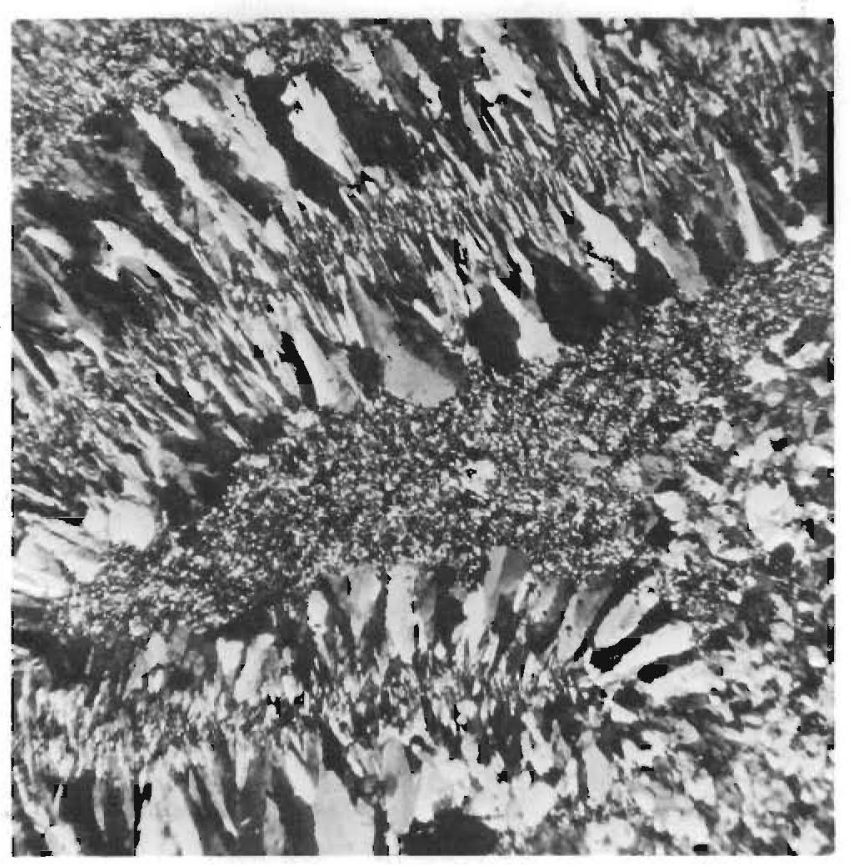

FIGURE 2

Microstructure of Plutonium Plastically Deformed (60\% by Compression) in the Beta Phase and then Isothermal1y Transferred at $80{ }^{\circ} \mathrm{C}$ 


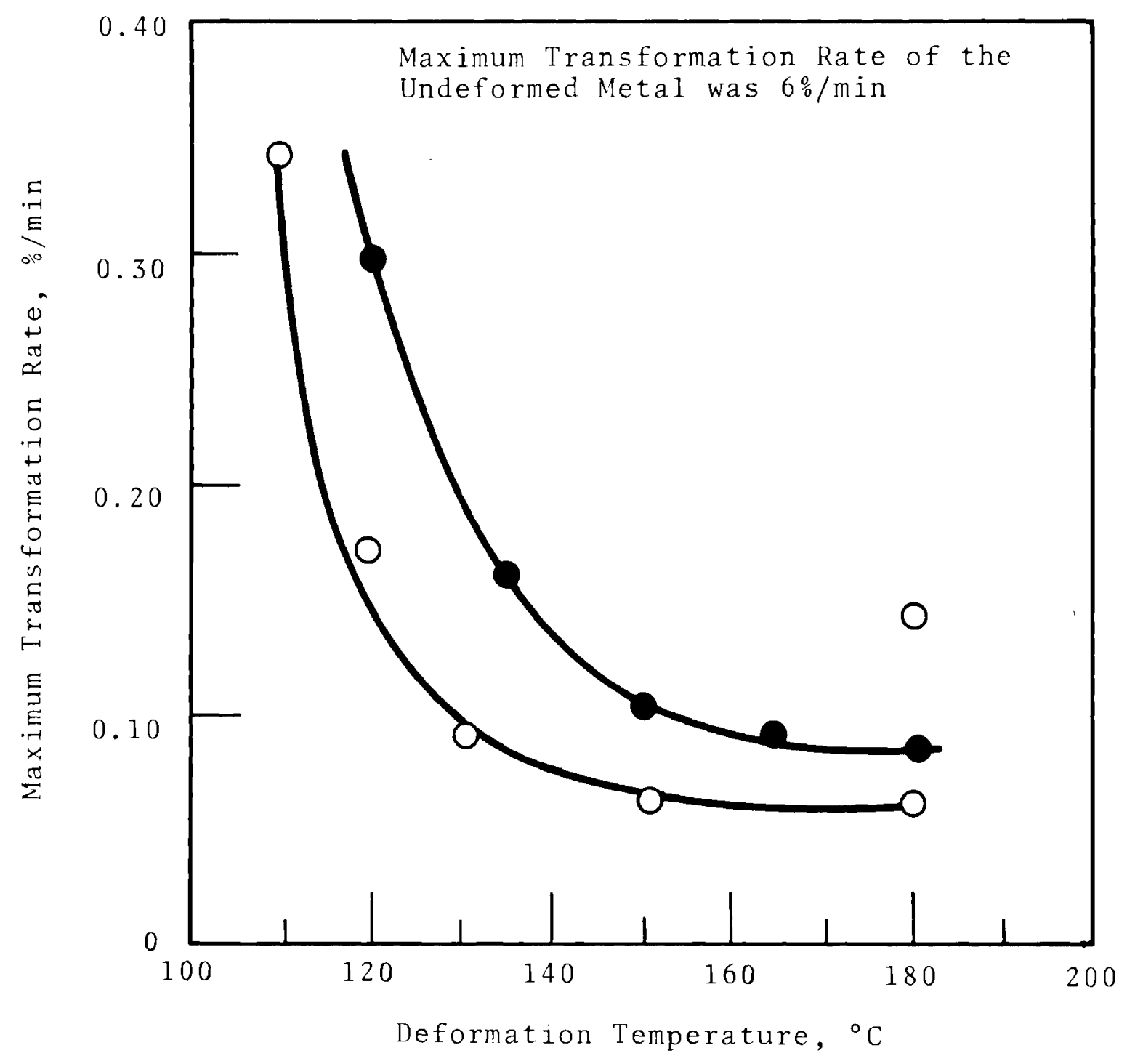

$$
\begin{gathered}
\text { Effect of Beta Deformation Temperature } \\
\text { on the Plutonium } \beta_{\alpha} \rightarrow \alpha \text { and } \\
\beta_{\gamma} \rightarrow a \text { Transformation Rates }
\end{gathered}
$$




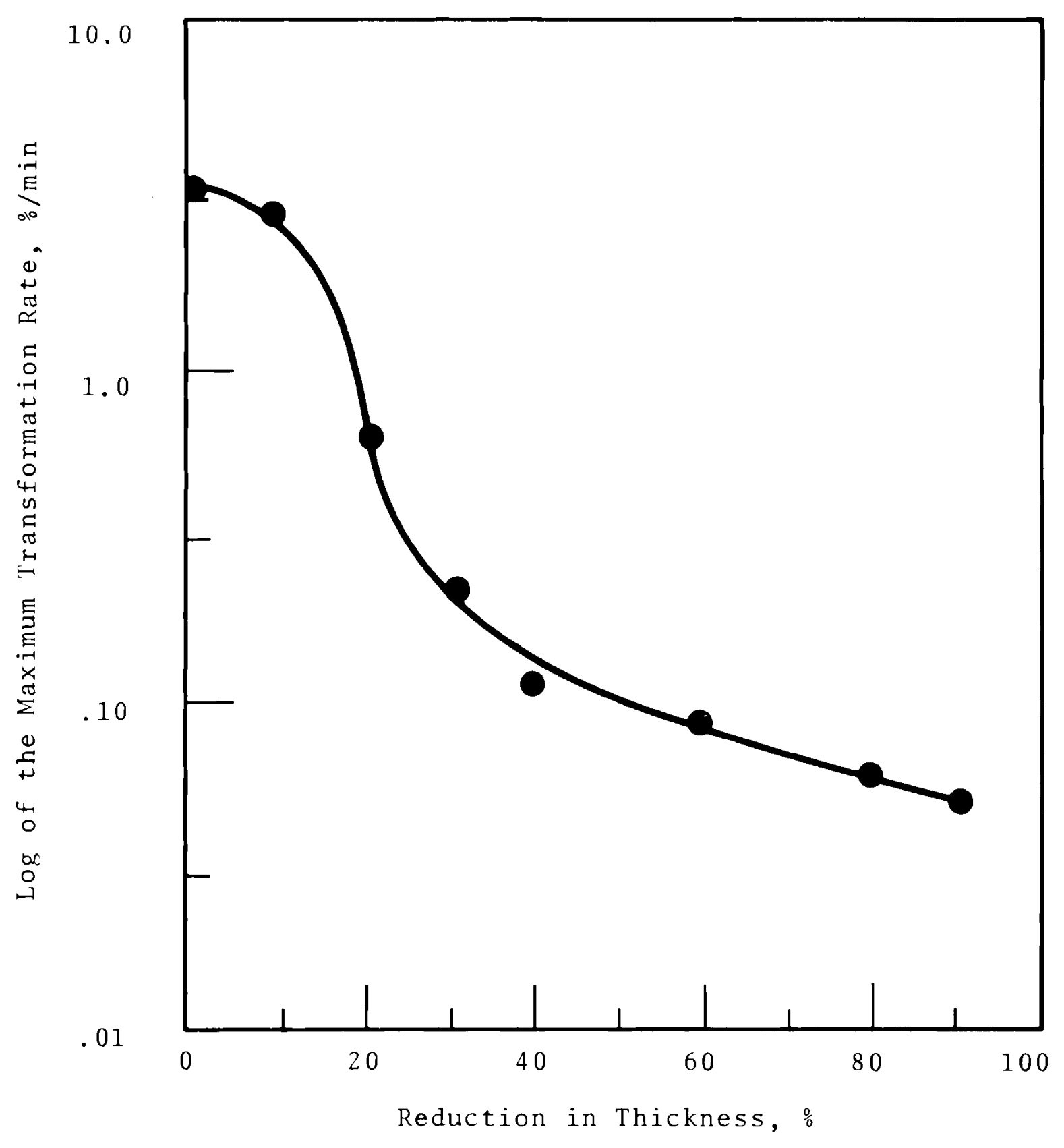

FIGURE 4

Effect of Beta Plastic Deformation at $150{ }^{\circ} \mathrm{C}$ on the $\beta_{\alpha} \rightarrow \alpha$ Transformation Rate at $80{ }^{\circ} \mathrm{C}$ 
of mechanical stabilization of parent phases in martensitic transformations apply.

INFLUENCE OF ALPHA PLASTIC DEFORMATION ON THE $\alpha \rightarrow \beta$ TRANSFORMATION KINETICS

Plastic deformation of the stable parent alpha phase accelerated the $\alpha \rightarrow \beta$ transformation at slow transformation rates. Specimens were compressed about $40 \%$ in thickness at $80^{\circ} \pm 10^{\circ} \mathrm{C}$. The representative $\alpha \rightarrow \beta$ isothermal reaction curves (Figure 5) clearly show the accelerating effect of the $\alpha \rightarrow \beta$ transformation rate by plastic deformation of the alpha phase material. The effects of the temperature of deformation and the amount of deformation on the $\alpha \rightarrow \beta$ transformation rate were not investigated.

Specimens of alpha that had been deformed by compression were annealed at $105^{\circ} \mathrm{C}$ to determine whether cold work could be annealed out of alpha plutonium. The $\alpha \rightarrow \beta$ transformation rate was used as in indirect measure of annealing since deformation accelerates the $\alpha \rightarrow \beta$ transformation rate. If annealing reduces the degree of cold work, it should also decrease the $\alpha \rightarrow \beta$ transformation rate. Seven specimens were compressed to one-half their initial thickness at $60^{\circ} \mathrm{C}$. They were then annealed for different times at $105^{\circ} \mathrm{C}$. The results showed that deformed alpha plutonium does annea 1 at $105^{\circ} \mathrm{C}$, as indicated by the time for start of transformation and by the $\alpha \rightarrow \beta$ transformation rate (Table I). About two weeks annealing time is required to regain the initial values for the undeformed alpha. These results imply that the deformation remaining in plutonium after compression is only in the form of residual stresses, which accelerate the $\alpha \rightarrow \beta$ transformation. CONCLUSIONS

Deformation of the stable parent phase results in a reduced transformation rate in phase changes that are martensitic. Results on Fe-Cr-Ni alloys substantiate this statement $(1-6,13,14)$. Russian investigators (12) used this inhibiting effect as a 


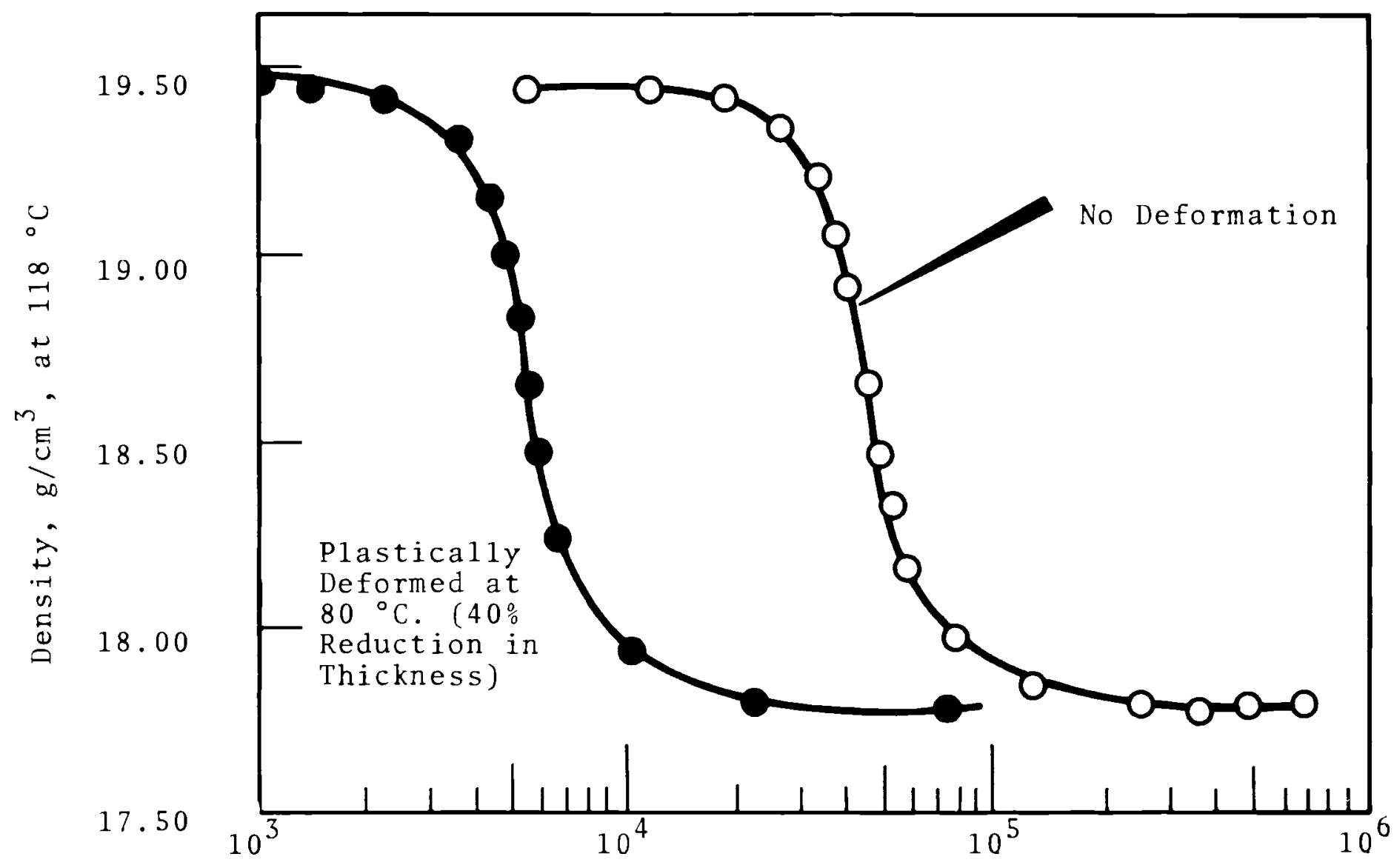

Time, Seconds

FIGURE 5

Effect of Alpha Plastic Deformation on the

Plutonium $\alpha \rightarrow \beta$ Transformation at $118{ }^{\circ} \mathrm{C}$ 


\section{TABLE I}

ANNEALING OF DEFORMED $\alpha$-PLUTONIUM AS REVEALED

BY THE INCUBATION TIME* AND THE TIME FOR

$\underline{50 \% \text { TRANSFORMATION OF THE } \alpha \rightarrow \beta \text { TRANSFORMATION }}$

\begin{tabular}{|c|c|c|}
\hline \multirow[b]{2}{*}{$\begin{array}{l}\text { Annealing Time } \\
\text { at } 105{ }^{\circ} \mathrm{C} \mathrm{hr}\end{array}$} & \multicolumn{2}{|c|}{$\begin{array}{l}\text { Times Required for } \alpha \rightarrow{ }^{\beta} \\
\text { Transformation at } 119{ }^{\circ} \mathrm{C}\end{array}$} \\
\hline & $\begin{array}{l}\text { Tncubation } \\
\text { Time } \\
\end{array}$ & $\begin{array}{l}\text { Time for } 50 \% \\
\text { Transformation }\end{array}$ \\
\hline 0 & 350 & 2240 \\
\hline 1 & 1300 & 4000 \\
\hline 2 & 2000 & 7200 \\
\hline 4 & 3000 & 9500 \\
\hline 24 & 3500 & 9800 \\
\hline 120 & 5300 & 12000 \\
\hline 700 & 5500 & 12300 \\
\hline
\end{tabular}


criterion for a martensitic transformation, because such an inhibiting effect of plastic deformation of the stable parent phase has been observed only for martensitic transformations and has not been observed for diffusional transformations. Plastic deformation always accelerates diffusional transformations (9) since it promotes both nucleation and growth. Accordingly, the plutonium $\beta \rightarrow \alpha$ transformation is martensitic because plastic deformation of the stable beta phase retards the $\beta \rightarrow \alpha$ transformation.

The accelerating effect of plastic deformation of the stable alpha phase on the plutonium $\alpha \rightarrow \beta$ kinetics is not in itself a sufficient criterion for categorizing this transformation. Although plastic deformation always accelerates diffusional transformations, small amounts of plastic deformation may accelerate martensitic transformations as we11. Thus, acceleration of a transformation by plastic deformation is consistent with either diffusional or martensitic transformations. Since alpha plutonium does not strain harden easily ${ }^{(15)}$, it can be reasoned that an insufficient number of dislocations is introduced by plastic deformation to block the $\alpha \rightarrow \beta$ transformation if it is martensitic. The number of dislocations introduced is sufficient to accelerate nucleation, even though the transformation may be martensitic.

According to the evidence of this report, the influence of plastic deformation of the stable, parent beta phase prior to the $\alpha \rightarrow \beta$ and $\beta \rightarrow \alpha$ phase changes in plutonium on the kinetics is consistent with other martensitic transformations. However, the $\alpha \rightarrow \beta$ transformation may be either diffusional or martensitic, but the $\beta \rightarrow \alpha$ transformation, which is retarded by plastic deformation, must definitely be a martensitic transformation. ACKNOWLEDGMENT

The author is very grateful to A. G. Graybea1, R. S. Hagan, A. S. Cole, and H. W. Arrowsmith for their assistance in the experimental work. 


\section{REFERENCES}

1. H. C. Fiedler, B. L. Averbach, and Morris Cohen. "The Effect of Deformation on the Martensitic Transformation in Austenitic Stainless Steel," Trans. Amer. Soc. Metals, vol. 47, p. 267. 1955 .

2. J. C. Shyne, V. F. Zackay, and D. J. Schmatz. "The Strength of Martensite Formed from Cold-Worked Austenite," Trans. Amer. Soc. Metals, vol. 52, p. 346. 1960.

3. V. Bharuchi, G. A. Mancini, G. W. Powe11, and J. W. Spretnak. "Transformation Kinetics in High Purity Iron and Some Iron Binary Alloys," Trans. Met. Soc., AIME, vol. 221, p. 498. 1961.

4. B. L. Averbach. "The Effect of Plastic Deformation on Solid Reactions, Part II, The Effect of Applied Stress and Strain on the Martensite Reaction," Cold Working of Metals, p. 290, American Society for Metals, Cleveland, 1959.

5. James F. Watson and Jack L. Christian. "A Study of Austenite Decomposition at Cryogenic Temperatures," Trans. Met. Soc., AIME, vol. 224, p. 998. 1962 .

6. J. S. Bowles and C. S. Barrett. "Crystallography of Transformation," in Bruce Chalmers (ed.), Progress in Metal Physics, pp. 1-41, Pergamon Press, London, 1952 .

7. C. J. McHargue and H. L. Yakel, Jr. "Phase Transformations in Cerium," Acta Met., vo1. 8, p. 637. 1960.

8. C. R. Houska, B. L. Averbach, and M. Cohen. "The Cobalt Transformation," Acta Met., vol. 8, p. 81. 1960.

9. B. L. Averbach. "The Effect of Plastic Deformation on Solid Reactions, Part I, Diffusion Reactions," Cold Working on Metals, p. 262, American Society for Metals, Cleveland, 1949.

10. A. H. Cottrell. "Tensile Properties of Unstable Austenite and its Low-Temperature Decomposition Products," J. Iron St. Inst., vo1. 151, p. 93. 1945.

11. A. W. McReynolds. "Effect of Stress and Deformation on the Martensite Transformation," J. Appl. Phys., vol. 20, p. 896. 1949 .

12. B. K. Sokolov, I. P. Sorokin, and A. I. Stregulin. Fiz. Metal Metallovid, vol. 17, p. 315. 1963.

13. G. B. Kurdymov et al. "The Effect of Prior Plastic Deformation on the Martensitic Transformation in an $\mathrm{Fe}-\mathrm{Cr}-\mathrm{Ni}$ Alloy," The Physics of Metals and Metallography, vol. 16, p. 85. 1959.

14. G. B. Kurdjumov. "The Nature of Martensitic Transformations," J.Met., vo1. 11, p. 449. 1949.

15. I. Ianniello. "The Recrystallization of Alpha-Plutonium," Trans. ASM, vo1. 57, p. 768. 1964. 


\section{Copy Number}

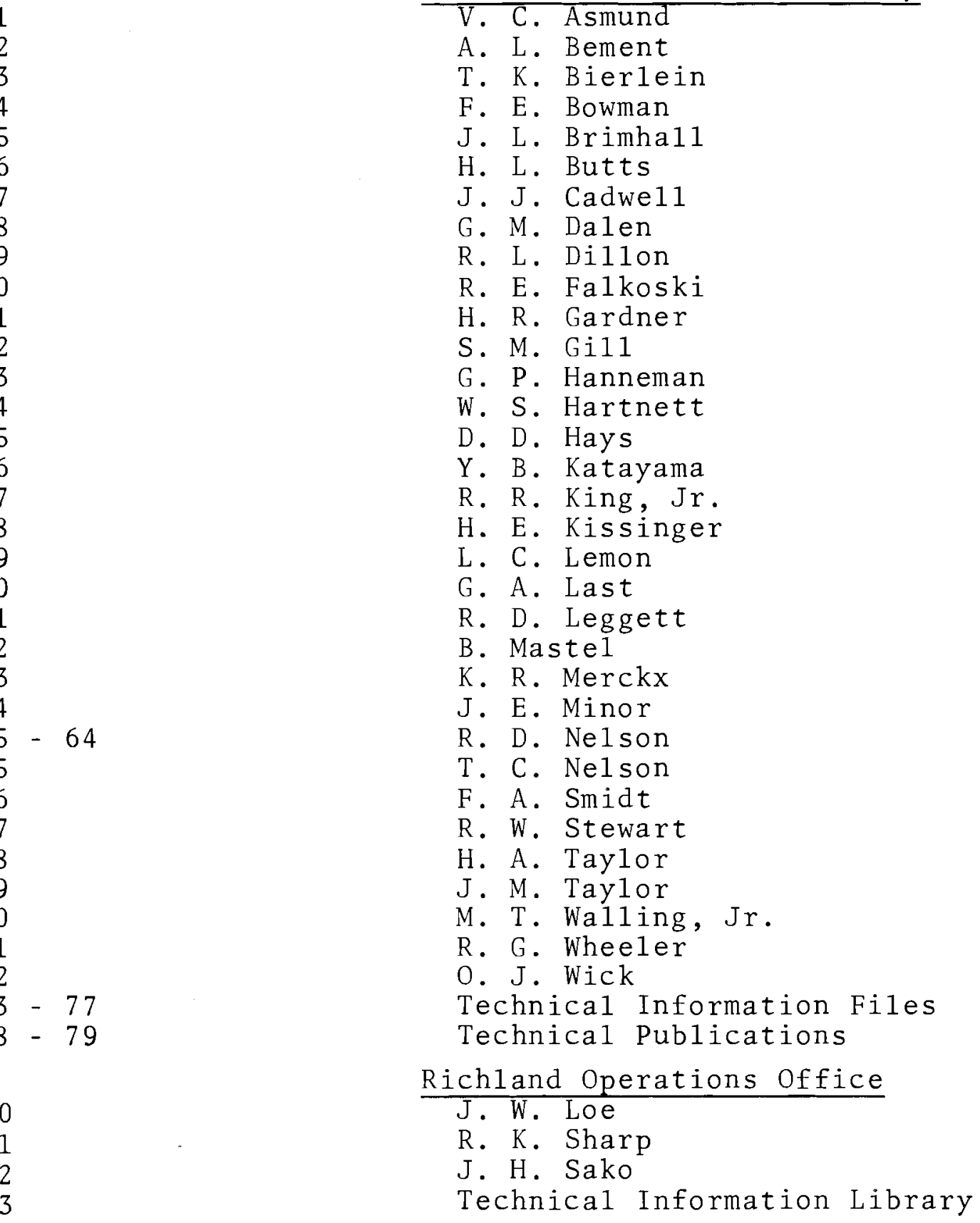

Pacific Northwest Laboratory

T. K. Bierlein

F. E. Bowman

J. L. Brimha11

H. L. Butts

J. J. Cadwe 11

G. M. Dalen

R. L. Dillon

R. E. Falkoski

H. R. Gardner

S. M. Gill

. P. Hanneman

. Hartnet

. D. Hays

R. D. Leggett

B. Maste 1

K. R. Merckx

J. E. Minor

R. D. Nelson

T. C. Nelson

F. A. Smidt

R. W. Stewart

H. A. Taylor

- M. Taylor

. T. Walling, Jr.

O. J. Wick

Technica1 Information Files

R. K. Sharp

Technical Information Library 
